\title{
LA CUARTA DIMENSIÓN DEL TIEMPO EN "PENA DE EXTRAÑAMIENTO" DE ENRIQUE LIHN*
}

\author{
THE FOURTH DIMENSION OF TIME IN "PENA DE EXTRAÑAMIENTO" \\ ("PAIN OF STRANGEMENT") BY ENRIQUE LIHN
}

JUAN ZAPATA GACITÚA***
MARIELA FUENTES LEAL ${ }^{* * * *}$

\section{RESUMEN}

En este artículo proponemos que el poema "Pena de extrañamiento" de Enrique Lihn constituye una reflexión teórica sobre la configuración espacio-temporal postmoderna y, desde la poesía, un esfuerzo por superar el tiempo espectral y acceder a una cuarta dimensión del tiempo.

Palabras clave: Enrique Lihn, poesía chilena, postmodernidad, tiempo espectral.

\section{ABSTRACT}

In this article we propose that the poem "Pena de extrañamiento" ("Pain of strangement") by Enrique Lihn constitutes a theoretical reflection about the postmodern

* Este artículo se inscribe en el Proyecto de Investigación "Enrique Lihn en el siglo XXI: Desplazamientos teóricos, críticos y analíticos". Proyecto DIUC N²10.062.045-1.0. Dirección de Investigación de la Universidad de Concepción. Investigador responsable: Dr. Juan Zapata Gacitúa. Co-investigadora: Dra. Mariela Fuentes Leal.

** El Dr. Juan Zapata Gacitúa, profesor de la Facultad de Humanidades y Arte en la Universidad de Concepción, falleció en abril de 2015. Su investigación sobre la obra de Enrique Lihn lo llevó a publicar diversos trabajos en su trayectoria académica y a unir su propia creación poética a su figura en Interiores/Exteriores. Este trabajo ha sido editado Post mortem y da término a nuestro último proyecto realizado a cuatro manos.

*** Dra. en Literatura Latinoamericana, Facultad de Humanidades y Arte, Universidad de Concepción. Concepción, Chile. Correo electrónico: mariefue@udec.cl

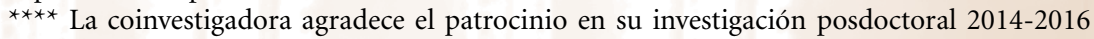
al Council on Latin American and Iberian Studies en el Whitney and Betty MacMillan Center for International and Areas Studies en la Universidad de Yale y también reconoce a la Comisión Nacional de Ciencia y Tecnología (CONICYT) y a la Universidad de Concepción. 
time-space configuration and, from poetry, an effort to overcome the spectral time and access a fourth time dimension.

Keywords: Enrique Lihn, Chilean poetry, postmodernism, spectral time.

Recibido: 27.06.14. Aceptado: 11.12.17.

\section{INTRODUCCIÓN}

$\mathrm{E}$

STE ARTÍCULO constituye la síntesis de una investigación sobre la obra de Enrique Lihn. Fue el último trabajo realizado junto a Juan Zapata que permite prolongar las dos líneas de investigación principales en las que estuvo trabajando durante treinta años. Por una parte, el estudio sistemático de la obra de Enrique Lihn y, por otra, la reflexión sobre el cambio de época, de la modernidad a la postmodernidad.

En realidad, fue la primera línea de investigación la que llevó naturalmente a la segunda. Ahora, en el siglo XXI, es posible comprobar que la significación de la obra del creador chileno radica en el hecho de que se situó en el eje de estos dos tiempos, para la civilización, para la cultura, para el arte y para la literatura; por esto, entonces, en un momento complejo y de crisis, aspecto que se materializa en toda su obra creativa, sobre todo, en su escritura poética, narrativa y crítica. Respecto a la reflexión sobre la postmodernidad, en sí misma compleja, es abordada de manera sistemática y acotada; así, se distingue las distintas formas que presentaba el cambio de paradigma a través de una perspectiva transdisciplinaria y desde dimensiones y conceptos asociados a pensadores específicos. Por ejemplo, como una Nueva Edad Media (Umberto Eco, 1990; Taichi Sakaiya, 1994; Georges Duby, 1995); arcaísmo (Régis Debray, 1996); cultura audiovisual (Giovanni Sartori, 1998); sociedad del conocimiento (Taichi Sakaiya, 1994); era del acceso (Jeremy Rifkin, 2000). Además, en el área de investigación, relacionada con las humanidades, las artes y las letras, era posible identificar una nueva estética, la cual aparecía con distintos nombres, los que surgen, también, de visiones específicas: antiestética (Hal Foster, 1993), neobarroco (Severo Sarduy,1987), estética de la desaparición (Paul Virilio, 1998), an-estética (Neil Leach, 2001), tecnoestética (Andrew Darley, 2002). Asimismo, se intentó definir un espacio-tiempo postmoderno.

De este modo, es en este contexto teórico específico, la configuración espacio-temporal postmoderna, en el que inscribimos este artículo, centrado en un fragmento de la inmensa labor creativa de Enrique Lihn, el 
poema "Pena de extrañamiento", que está incluido en el libro del mismo título (Lihn, 1986 pp. 7-10), pues él aparece como una reflexión sobre esa configuración y el esfuerzo por oponerse al tiempo espectral que ella genera y acceder a una cuarta dimensión del tiempo.

\section{LA CONFIGURACIÓN ESPACIO-TEMPORAL POSTMODERNA}

$\mathrm{Al}$ respecto, volvemos sobre dos trabajos escritos hace once años por Juan Zapata, los que profundizamos y actualizamos. En primera instancia, en una conferencia titulada "Humanidad, tecnología y reflexión teórica hacia el siglo XXI" (2003), se adelantan algunas ideas relacionadas con el impacto de las tecnologías postindustriales sobre el ser humano y el sentido de este proceso; así, se respondía a la siguiente pregunta: “¿En qué consiste la configuración espacio-temporal postmoderna?”. Respuesta en ese momento:

La reflexión de Baudrillard nos permite delimitar el problema de la influencia de la tecnología sobre las condiciones de vida del hombre postmoderno y aislar una dimensión específica: un espacio-tiempo postmoderno. Esto ha sido considerado desde una perspectiva teórica y práctica. Así, por ejemplo, David Harvey, desde una base económica y al definir a la postmodernidad como el paso desde el "fordismo" al "régimen de acumulación flexible", plantea que la comprensión del espacio y del tiempo en "la condición postmoderna", respecto al primero, se ha traducido en un nuevo interés por la teoría geopolítica, por la estética del lugar y por un deseo revivido por abrir el problema de la espacialidad a una consideración general; en tanto, respecto al tiempo, la percepción de él es efímera, veloz, instantánea, volátil, lo que conduce a una visión fragmentaria de la realidad, mediatizada por imágenes y simulacros. De este modo, el tiempo y el espacio, siguiendo a Paul Virilio en su libro La estética de la desaparición, como dimensiones materiales y tangibles, desaparecen en la vida social y para el pensamiento y la acción humana (Zapata G., 2003a, s/p).

Posteriormente, también en el año 2003, en la conferencia "La configuración espacio-temporal postmoderna en los estudios literarios", Zapata intenta proyectar esta configuración en los estudios literarios. De este modo, observa cómo las formas de la postmodernidad, antes señaladas, se manifestaban en la práctica académica, en los estudios literarios y en la crítica literaria. Además, el investigador reiteró la reflexión de algunos de los pensadores de fines del siglo pasado respecto a la configuración de 
espacio-tiempo postmoderna: Lyotard, Baudrillard, Virilio. Así, concluía hace once años:

En síntesis, la configuración espacio-temporal postmoderna y su proyección en los estudios literarios la vemos, además de los aspectos señalados, de la siguiente manera: desaparición de la noción de espacio físico y tiempo fragmentario; reflejado, por ejemplo, en Congresos de Literatura con mesas simultáneas, donde los asistentes se retiran apenas termina una conferencia y se trasladan a otra sala; por lo tanto, conocimiento fragmentario y fragmentado. Además, tiempo limitado para las ponencias, ante audiencias que no pueden o no quieren escuchar discursos extensos; por lo mismo, necesidad de trabajos breves. Conexión a través de Internet con personas que ya eran parte del pasado y con personas que, quizás, nunca se conocerán personalmente; difusión de los trabajos a escala global (Zapata G., 2003b, s/p) ${ }^{1}$.

Además, en términos muy específicos, la idea de tiempo-espacio postmoderno la sintetizaba Lyotard en su libro Lo inhumano. Charlas sobre el tiempo (1998); en la charla que lleva como título "Algo así como: 'Comunicación... sin comunicación”" (pp. 111-121), al oponer la concepción de espacio-tiempo moderna y postmoderna, a propósito de las crisis de las ciencias desde fines del siglo XIX: "En esta crisis, que se refiere a las condiciones del espacio y el tiempo (con sus dos expresiones, la moderna: ya no quedan más que el espacio y el tiempo, y la posmoderna: no nos quedan $n i$ siquiera el espacio y el tiempo)" (p. 118). Crisis que se proyecta hacia el arte y la literatura de vanguardia y que el filósofo resume al inicio de otra charla que tiene como título "Representación, presentación, impresentable" (pp. 123-131):

No es sólo la fotografía la que hizo "imposible" el oficio de la pintura. Sería lo mismo decir que la obra de Mallarmé o la de Joyce son réplicas al progreso del periodismo. La "imposibilidad" proviene del mundo tecnocientífico del capitalismo industrial y posindustrial. Ese mundo necesita la fotografía y casi no necesita la pintura, así como le es más necesario el periodismo que la literatura. Pero, sobre todo, no es posible sino en la retirada de los oficios "nobles" que pertenecen a otro mundo, y en la misma retirada de éste (p. 124).

\footnotetext{
${ }^{1}$ En estas respuesta y síntesis se tuvo presente teóricos y textos específicos: Baudrillard (1994, 1997), Harvey (1993), Virilio (1996, 1997a, 1997b, Lyotard (1987, 1989, 1998).
} 
La reflexión anterior de Lyotard permite entender más claramente, desde el siglo XXI, las obras de la vanguardia artística y literaria del siglo XX, pues en varios fragmentos del libro antes citado, el autor reitera que el sentido de ellas se tradujo en dar respuestas a preguntas específicas: ¿Qué es la pintura o el cuadro?, ¿qué significa pintar o escribir?, ¿qué es un cuadro o una creación literaria? Además, hoy día da respuesta a una observación de un profesor chileno, quien dijo que Lihn había llevado a la poesía chilena a un callejón sin salida; asimismo, podría postularse que el poema "Pena de extrañamiento" constituye una respuesta a las preguntas anteriores.

De esta forma, con algunos textos teóricos que aparecen en los primeros años del siglo XXI, ampliamos y profundizamos en el estado de la configuración espacio-temporal postmoderna.

En primer lugar, Zygmunt Bauman en el "Prólogo" de su libro Modernidad líquida (2009), considera la relación entre espacio y tiempo como origen de la idea misma de modernidad:

La modernidad empieza cuando el espacio y el tiempo se separan de la práctica vital y entre sí, y pueden ser teorizados como categorías de estrategia y acción mutuamente independientes, cuando dejan de ser -como solía serlo en los siglos premodernos- aspectos entrelazados y apenas discernibles de la experiencia viva, unidos por una relación de correspondencia estable y aparentemente invulnerable (p. 14).

Más adelante, en el capítulo 3, "Espacio/Tiempo" (pp. 99-138), profundiza en esa relación. Así, en el apartado "Cuando los extraños se encuentran con extraños (pp. 102-106), percibe cómo los hábitos y la comunicación entre las personas en la ciudad moderna van configurando la dimensión de un presente continuo, absoluto, o tiempo instantáneo:

El encuentro entre extraños es un acontecimiento sin pasado. Con frecuencia es también un acontecimiento sin futuro (se supone y se espera que esté libre de un futuro), una historia que, sin dudas, no "continuará", una oportunidad única, que deber ser consumada plenamente mientras dura y en el acto, sin demora y sin postergaciones para otra ocasión (p. 103).

A continuación, en el apartado "La modernidad como historia del tiempo" (pp. 118-122) reitera la idea adelantada en el "Prólogo" respecto a que la modernidad está unida a la idea de tiempo y en relación a las transforma- 
ciones de las tecnologías que desplazan a los seres humanos en el espacio ${ }^{2}$. En seguida, en el mismo apartado, se refiere al inicio de la modernidad y a la progresiva separación que van experimentando las dimensiones de espacio y tiempo en función de las nuevas tecnologías y su objetivo final de la aceleración y de la conquista de la Tierra:

La relación entre tiempo y espacio sería, a partir de entonces, mutable y a significar máquinas más rápidas. Los movimientos acelerados significaban espacios más grandes, y acelerar los movimientos era la única manera de agrandar el espacio. En este caso, la "expansión espacial" era el nombre del juego, y el espacio era la apuesta: el espacio era el valor; el tiempo, la herramienta (p. 121).

Después, en el apartado "De la modernidad pesada a la modernidad liviana" (pp. 122-127), considera el cambio de época desde la transformación de la economía y, asignándole otro nombre o forma a la modernidad, la define como "la era del hardware" o "modernidad pesada", en oposición a "la era del software" o modernidad liviana o líquida y con la absoluta importancia de la variable tiempo sobre el espacio e, incluso, la desaparición de éste en la gestión productiva.

De esta manera, en el apartado siguiente, "La seductora levedad del ser" (pp. 127-132), profundiza en la idea del tiempo instantáneo en la época del software y su proyección en la literatura contemporánea:

Milan Kundera describió "la insoportable levedad del ser" como eje de la tragedia de la vida moderna. La levedad y la velocidad (jjuntas!) fueron elegidas por Italo Calvino, el inventor de esos personajes completamente libres (libres gracias a su elusividad, que imposibilita cualquier intento de atraparlos) -el barón rampante y el caballero invisible- que funcionan como encarnaciones últimas del eterno poder emancipador del arte literario (p. 128).

Así, la cita anterior permite reafirmar el objetivo de este artículo en cuando a considerar que desde la literatura y, específicamente, desde el tex-

\footnotetext{
${ }^{2}$ Agrega Bauman: "En los tiempos olímpicos de Grecia nadie pensaba en categorías o récords olímpicos, por no hablar de romper esos récords. Hizo falta la invención de algo diferente de los músculos humanos o animales para que existieran esas ideas y para que se concibiera y se llevara a la práctica la decisión de asignar importancia a las diferencias de la capacidad de desplazamiento de los diversos individuos -es decir, para que terminara la prehistoria del tiempo y empezara la historia del tiempo-. La historia del tiempo comenzó con la modernidad. Por cierto, la modernidad es, aparte de otras cosas y tal vez por encima de todas ellas, la historia del tiempo: la modernidad es el tiempo en el que el tiempo tiene historia" (p. 119).
} 
to poético de Enrique Lihn, es posible deducir consideraciones que aluden explícita e implícitamente a la configuración espacio temporal actual.

En el último apartado del capítulo 3, "La vida instantánea" (pp. 132138), y en directa relación a la dimensión temporal, la duración, que tematiza y materializa el poema de Enrique Lihn, define la noción de instantaneidad:

La instantaneidad (anular la resistencia del espacio y "licuificar" la materialidad de los objetos) hace que cada momento parezca infinitamente espacioso, y la capacidad infinita significa que no hay límites para lo que puede extraerse de un momento... por breve y "fugaz" que sea. (...)

La modernidad "sólida" planteaba que la duración eterna era el motor y el principio de toda acción; en la modernidad "líquida", la duración eterna no cumple ninguna función. El "corto plazo" ha reemplazado al "largo plazo" y ha convertido la instantaneidad en ideal último. La modernidad fluida promueve al tiempo al rango de envase de capacidad infinita, pero a la vez disuelve, denigra y devalúa su duración (pp. 133$134)^{3}$.

Por esto, en directa relación al poema objeto de nuestro comentario, sintetiza Bauman:

El advenimiento de la instantaneidad lleva a la cultura y a la ética humana a un territorio inexplorado, donde la mayoría de los hábitos aprendidos para enfrentar la vida han perdido toda utilidad y sentido. Según la famosa expresión de Guy Debord, "los hombres se parecen más a su época que a sus padres". Y los hombres y las mujeres de hoy difieren de sus padres y de sus madres porque viven en su presente "que quiere olvidar el pasado y ya no parece creer en el futuro" (pp. 137-138).

Así, la reflexión de Bauman sobre la "modernidad líquida" conduce a la idea de nihilismo, desarrollada por escritores y teóricos franceses contemporáneos. En efecto, de la misma manera que Bauman, el narrador, poeta y ensayista Michel Houellebecq, constata la situación negativa de los seres humanos producto de las tecnologías, principalmente, de la información y

\footnotetext{
${ }^{3}$ Como la mayoría de los teóricos que se reflexionan respecto a la configuración espaciotemporal postmoderna, Bauman advierte respecto a las consecuencias más profundas que tiene la evolución de ella: "La devaluación de la inmortalidad sólo puede augurar una revolución cultural, posiblemente el hito más decisivo de la historia humana. El paso del capitalismo pesado al liviano, de la modernidad sólida a la fluida, puede resultar un desvío aun más radical y seminal que el advenimiento del capitalismo y la modernidad misma, considerados hasta el momento los hitos cruciales de la historia humana desde la revolución neolítica” (p. 135).
} 
sus efectos sobre la literatura; sin embargo, ve alguna salida al respecto. En efecto, en la primera sección de su libro Intervenciones (2011), "Aproximaciones al desarraigo" (pp. 21-43), apartado "El mundo como supermercado y como burla" (pp. 34-39), en el contexto de la sociedad del espectáculo y de la lógica del hipermercado, percibe a la literatura en oposición a ellas y superándolas desde la realidad del libro impreso y como objeto físico, en oposición al flujo ininterrumpido de la información:

Porque un libro sólo puede apreciarse despacio; implica una reflexión (no en el sentido de esfuerzo intelectual, sino sobre todo en el de vuelta atrás); no hay lectura sin parada, sin movimiento inverso, sin relectura. Algo imposible e incluso absurdo en un mundo donde todo evoluciona, todo fluctúa; donde nada tiene validez permanente: ni las reglas, ni las cosas, ni los seres. La literatura se opone con todas sus fuerzas (que eran grandes) a la noción de actualidad permanente, de presente continuo. Los libros piden lectores; pero estos lectores deben tener una existencia individual y estable: no pueden ser meros consumidores, meros fantasmas; deben ser también, de alguna manera, sujetos (pp. 37-38).

Por esto, frente a la imposibilidad de la lectura y de lectores de libros, y de seres humanos en tanto sujetos, agrega:

Con mayor motivo, no pueden desempeñar ese papel frente a otro ser. No cada cual, movido por una dolorosa nostalgia, continúa pidiéndole al otro lo que él ya no puede ser; cada cual sigue buscando, como un fantasma ciego, ese peso del ser que ya no encuentra en sí mismo. Esa resistencia, esa soledad es espantosa (p. 38).

Es decir, la cita anterior nos remite directamente al texto de Enrique Lihn, a su versión no publicada y al título posible que pensó el poeta: "El fantasma de carne y huesos", incluido en Derechos de autor (Lihn, 1981, s/p).

Por lo tanto, en el contexto del pensamiento teórico y crítico francés actual, las ideas de Houellebec, ligadas al nihilismo en cuanto crisis de los conceptos de tiempo y espacio, se complementan con las de Francois Meyronnis. De este modo, se remite al pensamiento teórico del físico y escritor en el capítulo "El hueco en el tiempo" (pp. 175-220) de su libro L'Axe du Néant (2003), donde aparece otra visión, o forma, de la época actual, bajo la noción de "era del Gran Cero" y a la postmodernidad concebida como "nihilismo cumplido", producto de las tecnologías industriales y postindustriales, las que conducen a la dimensión de "tiempo espectral", "fantasmático" o "presente perpetuo". 
En ese trabajo, Meyronnis presenta una visión de las reflexiones sobre el tiempo desde los filósofos griegos hasta Paul Virilio, pasando por San Agustín, Kant y Nietzsche; se refiere a la visión del tiempo tal como se concibe en la percepción común: como una línea. En seguida, profundiza en la visión de Virilio, quien demuestra cómo la velocidad de la luz, producto del desarrollo científico y tecnológico, desde fines del siglo XIX, ha conducido a una catástrofe haciendo colapsar las categorías de presente, pasado y futuro, lo que se traduce en el advenimiento de un tiempo espectral, tiempo fantasmal o presente perpetuo y a la instantaneidad absoluta:

Otro aspecto de la catástrofe, correlacionada con el limamiento de la vida histórica : los lugares, no importa cuáles, y las distancias geográficas que se encuentran entre ellos, sufren una terrible devaluación en beneficio de la potencia extra-territorial de la red. Como dice Paul Virilio: "Aquí no es más, todo es ahora" (pp. 197-198).

Sin embargo, Meyronnis ve también una salida a la catástrofe desde la reflexión de Heidegger; específicamente, desde la conferencia "Tiempo y Ser", donde éste postula una cuarta dimensión del tiempo o tiempo intercalado o espacio libre del tiempo, el cual define en varios pasajes de su ensayo. Por ejemplo:

La cuarta dimensión del tiempo une las tres primeras y, dice el texto de la conferencia, ella no se les une sino "en la medida donde ella libera y despliega un lejano".

Cuando la cuarta dimensión no libera y no despliega ningún lejano, esto virtualiza el presente. En este nuevo contexto el deslumbramiento epifánico da lugar, sobre el fondo de obstrucción, a un sonambulismo convulsivo. Aquél en el que entran los vivos de la especie humana en la era del Gran Cero (p. 208).

En la visión de Meyronnis, es la poesía y el enfrentamiento con la nada lo que permite acceder a esta cuarta dimensión del tiempo; todo esto, más allá de la percepción occidental del tiempo y en directa relación con la filosofía oriental.

Las transformaciones tecnológicas planetarias y su incidencia en la cultura, la literatura y la poesía han sido, también objeto de reflexión desde el pensamiento creativo y teórico latinoamericano desde fines del siglo XX e inicios del siglo XXI. Así, Octavio Paz, en el Capítulo I, "La modernidad y sus desenlaces", apartado 1, "La nueva analogía: poesía y tecnología", del 
libro El signo y el garabato (1983) plantea que los nuevos medios de comunicación harían que la poesía volviera a su origen oral y con un sentido de ceremonia colectiva; esto, para la poesía norteamericana y latinoamericana, pues constata que en Francia se privilegia la dimensión escrita de la poesía. No obstante esta diferencia entre Europa y América, concluye:

La técnica cambia a la poesía y la cambiará más y más. No podía ser de otro modo: su intervención afecta tanto a la trasmisión y recepción de poemas como a los métodos para componerlos. Pero esos cambios, por más profundos que nos parezcan, no la desnaturalizan. Al contrario, la devuelven a su origen, a lo que fue al principio: palabra hablada compartida por un grupo (Paz, 1983, p. 19).

Además, de la reflexión de Octavio Paz, una buena síntesis del problema cultural latinoamericano en el contexto de la globalización económica y tecnológica, y su proyección hacia el dominio de la literatura, se encuentra en la serie de trabajos incluidos en Latin American Philosophy Currents, Issues, Debates (2003), editado por Eduardo Mendieta, donde los ensayistas se interrogan sobre la posibilidad de un pensamiento filosófico y teórico latinoamericano. Al respecto, y en relación a la variable tecnológica, Santiago Castro-Gómez señala:

(...) la gran mayoría de la población en Latinoamérica ha accedido a la modernidad- no a través de la educación o de los programas letrados e ideológicos de las vanguardias intelectuales, sino a través de las nuevas tecnologías de la información. En contraposición a lo sucedido en Europa, la consolidación de la modernidad cultural en Latinoamérica no produjo cine, radio y televisión; pero, precisamente, debido a estos medios. En este sentido se podría hablar de una "modernidad periférica", en la que diferentes tiempos y lógicas se mezclan (p. 69)4.

\footnotetext{
${ }^{4}$ En relación al pensamiento crítico y teórico latinoamericano respecto al tema analizado, remitimos a los clásicos Culturas híbridas (1990) de Néstor García Canclini, La ciudad letrada (1990) de Ángel Rama y a las perspectivas más actuales de Beatriz Sarlo en Escenas de la vida posmoderna (1990), Vicente Lecuna, en La ciudad letrada en el planeta electrónico (1999), Lidia Santos, en Kisch tropical (2004), Eduardo Subirats, en Una última visión del paraíso (2004).
} 


\section{PENA DE EXTRAÑAMIENTO: EL LIBRO Y LA CRÍTICA}

Los trabajos críticos en relación al libro coinciden en contextualizarlo en la serie de textos, libros y poemas, que responden a la noción de "poesía de paso"; además, se enfatiza el carácter político de algunos de los textos en relación a la situación política chilena hacia fines del siglo XX; por ejemplo, Shopf (1986), Foxley (1995), Travis (2007); por su parte, Lastra (1986), presenta una visión amplia del poemario $y$, aunque también se refiere a la dimensión política, destaca principalmente la idea de lo fantasmal, explícita en el poema y en directa relación con nuestra perspectiva teórica; de la misma manera, Garrido (2010); asimismo, Pohlhammer (1987) caracteriza a la escritura poética de Lihn desde el libro y alude al problema del tiempo, existencial y personal del poeta, con un carácter anticipatorio. Sin embargo, en concordancia con nuestra hipótesis y en el contexto de la dimensión nihilista que presenta Pena de extrañamiento, Carmen Foxley lo percibe como un ensayo al relacionarlo con la reflexión de Benjamin sobre el Barroco: "Eso hace de este libro una suerte de ensayo en el que se tematiza la melancolía como rasgo característico de la modernidad, tal como Benjamín lo destaca al estudiar el Barroco" (Foxley, 1995, p. 206); idea que reitera hacia el final de su análisis del libro: "Para terminar quisiera resumir diciendo que $P E$ se organiza como un ensayo sobre las diversas facetas de la melancolía, actitud básica del hablante y de todos los personajes que deambulan en el escenario de los textos, lo que nos remite a Benjamín y a las relaciones que se pueden establecer entre la modernidad y el Barroco, momentos históricos en los que la melancolía es el síntoma de una crisis cultural" (Foxley, 1995, p. 225).

En nuestra visión, concordamos con los juicios críticos anteriores y pensamos que, efectivamente, este poemario recoge características temáticas y estructurales que están presentes en la mayor parte de la obra poética anterior y posterior de Lihn; un espacio significativo se le otorga a una dimensión que singulariza su escritura: la remisión constante a otros textos y sistemas semióticos. Los poemas incluidos, en su gran mayoría, tienen como referente las ciudades de Nueva York, Barcelona y Santiago, continuando, de esta forma, con el proceso escritural iniciado por Lihn en Poesía de paso (1966), en el que el sujeto que recorre las ciudades europeas responde en forma instantánea a los estímulos que éstas le presentan, lo que se traduce en textos breves y objetivos que se acercan a las artes visuales: "Ciego en el Subway" (p. 22), "Manhhatan, paso" (p. 30), son algunos ejemplos de este tipo de poemas. Así, se establece una filiación obvia de este libro con $A$
PENA DE

EXTRAÑAMIENTO

Enrique Lihn

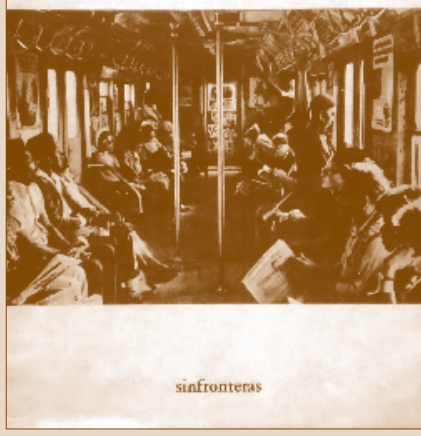


partir de Manhattan (1979), ya que, igual que en ese libro, hay constantes alusiones a la pintura:

Desnudar al desnudo

fue lo que hizo Degas "("Woman Bathing in a

Shalow Tub") (p. 14).

En el poema "Kandinsky 1904", la relación intersemiótica muestra la situación límite a la que llegó el arte contemporáneo en su esfuerzo por interrogarse sobre la constitución de sus materiales de trabajo y respecto del funcionamiento del objeto artístico:

La relación de unas cosas con otras iba borrando, poco a poco, las cosas Versos sin palabras Formas sin figuras.

No bien partía un barco de oro de la orilla cuando ya no era orilla ni barco ni partía (p. 16).

En este mismo contexto, el poema "La Efímera Vulgata" (pp. 35-41) traduce en lenguaje verbal las imágenes fotográficas de un libro del mismo nombre 5 .

Aun cuando el mismo libro sugiere, desde la portada, que se sitúa en el espacio de la ciudad moderna desarrollada (fotografía del metro), el espacio local hispanoamericano está presente, también, a través de la barbarie y el absurdo, en la referencia directa al contexto inmediato y en la relación intertextual con Lewis Carroll, en los poemas "Disparan en la noche" y "Alicia en el país de las pesadillas", que citamos:

La niña, que por su nueva situación no lo era, llegó a una madurez precoz

pues hasta ahora no había visto los barrios pobres de Londres de los comienzos de la era industrial, ni los prostíbulos ni los hospitales en que hacen cola

los agonizantes

Eso y otras insuficiencias londinenses fue lo que vio ahora en un país subdesarrollado (p. 53).

\footnotetext{
${ }^{5}$ Este poema fue, recientemente, publicado como libro, integrando las fotografías de Luis Poirot de las cuales surgió el poema (Lihn/Poirot, 2012).
} 
En este poema, más allá de la remisión al referente histórico y político de esos años en Chile, muestra el carácter de espacio por fundar que adquiere ese espacio subdesarrollado en relación a su otro desarrollado, su atraso irremediable respecto de él y, finalmente, lo arbitrario del concepto de tiempo como una dimensión lineal y con destino, la relatividad de los conceptos de tiempo y espacio y su actualización en el espacio intemporal del poema. Sin embargo, en el siglo XXI, esas categorías terminan por desaparecer en el contexto de la globalización, en función de las nuevas tecnologías y hace obsoletas las visiones modernas del tiempo y del espacio al respecto ${ }^{6}$.

\section{4. “PENA DE EXTRAÑAMIENTO”: EL POEMA}

El poema que inicia el libro, "Pena de extrañamiento", como ya lo señalamos, fue incluido con escritura manuscrita en el libro artesanal Derechos de autor (1981); después de su primera edición convencional (1986) fue antologado por el mismo poeta en Mester de Juglaría (1987). El texto, en la primera edición, aparece con el título de "El fantasma de carne y hueso" $y$, en relación a la versión definitiva, se percibe el cambio de enunciados y palabras que privilegian la dimensión fónica del poema ${ }^{7}$. Además, temática, estructural e, incluso, gráficamente, guarda relación con dos poemas fundamentales de su obra anterior; en primer término, con el poema "La pieza oscura", del libro del mismo nombre (1963), que muestra el esfuerzo por la recuperación de la infancia a través de un trabajo sobre la memoria y en el lenguaje poético. En segundo término, el texto remite al poema "Beata Beatrix", del libro Por fuerza mayor" (1975). "Beata Beatrix" surge de un cuadro del pintor prerrafaelista Dante Gabriel Rossetti; escrito en el verano

\footnotetext{
${ }^{6}$ Por ejemplo, la de Carmen Foxley, quien establece un sentido diferente del tiempo para las distintas ciudades tematizadas en Pena de extrañamiento: "Sin embargo, hay matices de la experiencia temporal que dependen del espacio referido. Cuando se trata de Manhattan se habla de un presente sin futuro y los hechos se cuentan como si ocurrieran ahora, cuando se trata de Barcelona sentimos el pasado apegado a esos monumentos, que parecen trabajar doblemente para conquistar el presente, y cuando se trata de Chile hay menciones de mal augurio para el futuro" (Foxley, 1995, p. 213).

${ }^{7}$ Los fragmentos del poema, en su versión manuscrita, en Derechos de autor están separados y enmarcados por viñetas, figuras o diseños que muestran flores, plantas o enredaderas; en definitiva, elementos naturales. Además, coexisten con la escritura, fotografías clásicas de los edificios representativos de Nueva York. Asimismo, se ve la figura de un hombre de otra época, atacado y abrumado, y la idea del fantasma. Termina el poema con una fotografía de la ciudad y la fecha de la escritura del texto: N.Y. enero 1981.
} 
de 1974, es "un largo poema sobre el vacío, la ausencia, la declinación, la decadencia, la muerte", dice Lihn en una entrevista (Maack, 1985, v.).

Los tres poemas tienen un carácter narrativo y están construidos según los procedimientos de la retórica: un tema central es recogido con variaciones dentro del poema; de esta forma, el sentido principal surge a partir de las relaciones que establece el lector en el proceso de la lectura, integrando en él las relaciones microtextuales. En los dos textos el tiempo aparece como uno de los ejes semánticos fundamentales y con un signo negativo, pues es lo irrecuperable o sólo recuperable parcialmente por medio de la memoria y el lenguaje poético. De este modo, "Pena de extrañamiento" muestra la imposibilidad de la recuperación del tiempo pasado y de los sujetos y lugares relacionados con ese tiempo:

Se congelan lágrimas que son de frío pero que memorizan, asimismo, a John Lennon

Reconozco la nieve de antaño, que cae sobre Blecker Street en este día acrónico mientras se hace de noche a la velocidad simultánea del vuelo de un murciélago y pasan películas de mi tiempo en mi barrio (p. 8).

El tiempo es recuperado en forma artificial a través de la fotografía y del cine y precariamente en la memoria y la poesía: la ausencia sigue presente ${ }^{8}$. Pero, sobre todo, en el poema aparecen palabras, conceptos y dimensiones que están en directa relación con la reflexión de los teóricos, antes citados, que más claramente se han ocupado de la configuración espacio-temporal postmoderna y que leemos en fragmentos del texto poético.

En primer lugar, vemos fragmentos y enunciados que nos remiten a las ideas de instantaneidad, presente absoluto y disolución del ser y de la identidad considerados por Bauman y Houellebecq:

${ }^{8}$ En la "Conversación inconclusa con Enrique Lihn (21 de junio de 1988)", con Cánovas y otros, Lihn reflexionaba: "O sea, para mí la poesía es una relación anómala con la realidad, que pone primeramente en tela de juicio esta categoría. Porque es una relación particular, específica con un lugar determinado, con todo como si estuvieras ahí. Pero de ese lugar tú te vas a ir, porque ése ha sido el destino de mi viaje, en ese lugar tú no estuviste y sabes que años atrás ese lugar era otro y todo lo que había allí ya no existe. Entonces, es un espacio del fantasma elevado al cubo, que produce un tipo de excitación... Es lo más cerca, yo creo, de una experiencia de la muerte." (p. 6). 
En una barraca, cerca de Nueva York, el martillero liquidó el

Saldo de su negocio

-un stock de fotografías antiguas-

ofreciéndolas a gritos en medio de la risotada de todos:

Antepasados instantáneos, por unos centavos

Esos antepasados eran los míos, pues aunque los adquirí a vil precio no tardaron, sin duda, en obligarme a la emoción

ante el puente de Brooklyn (p. 7).

En segundo lugar, y en relación al punto anterior, aparecen los elementos naturales y tecnológicos vinculados con las ideas de espacio y tiempo, que conducen a la reflexión de Virilio sobre la velocidad y la estética de la desaparición, asociada por el teórico a Georges Melies, y a la noción de catástrofe:

Como si me retuviera algún negocio en la ciudad veo a Cary Grant e Irene Dunne que acaban de morir en una vieja comedia víctimas del capricho de uno de los primeros automóviles deportivos (la máquina del glamour) Sigo sus apariciones y desapariciones - una cita de Melies en la magia blanca y sonora de Hollywoodla sorpresa de esta pareja en otro tiempo ideal cuando el paisaje se espejea en ellos -los transparentes- por gracia del celuloide (p. 8).

En tercer lugar, está la reflexión sobre el tiempo y la duración a la cual se refieren todos los autores teóricos y la condición fantasmal observada por ellos y detectada por la crítica sobre el poeta y los textos que comentamos:

Esta ciudad no existe para mí ni yo existo para ella allí, en ese punto en que los tiempos convergen bajo la especie de la Duración (p. 9).

En cuarto lugar, de manera fundamental, fragmentos del poema se relacionan con el pensamiento de Meyronnis y su ensayo, antes citado, sobre la cuarta dimensión del tiempo:

La isla dispone de fantasmas artificiales con que llenar los huecos de la contra-historia Ellos ocupan en la memoria, con la naturalidad que ésta se permite en relación a la nada (p. 7). 
De esta forma, la escritura y el lenguaje realizan en sí mismos una reflexión sobre la cuarta dimensión del tiempo y el enfrentamiento con la nada; es decir, se percibe una escritura que desaparece en la medida que se escribe: una afirmación y su negación inmediata, lo que se presenta en varios enunciados en el poema; por ejemplo, en la última línea de él: "cuando me vaya y no me vaya de aquí" (p. 10).

Así, igual que Lihn modificó el título del texto desde la versión manuscrita a la versión final, perfectamente, otro posible título para él podría ser "La estética de la desaparición" o "El eje de la nada". De esta manera, el poeta Lihn se convierte en teórico, desplaza su oficio hacia una práctica crítica y reflexiva y, nos parece, que su obra y el poema específico antes comentado constituyen el esfuerzo por superar el tiempo espectral y la búsqueda de la cuarta dimensión del tiempo que es, en el fondo, también, la poesía. Con esto, Lihn, hacia la segunda mitad del siglo XX, desplazaba la literatura y, en este caso, a la poesía hacia un Nuevo Paradigma Estético ${ }^{9}$, dando una respuesta a las preguntas que, según Lyotard, se planteaba el arte de vanguardia; en otras palabras, con "Pena de extrañamiento", el poeta chileno, en la misma línea de un pensador del siglo XXI como Meyronnis, responde las preguntas: ¿qué es un poema?, ¿qué significa escribir? Es enfrentarse con la Nada. En síntesis, aunque en este trabajo focalizamos nuestro análisis en un poema específico de Enrique Lihn, nos parece evidente que otros libros y poemas de su extensa obra creativa son susceptibles de ser leídos desde el siglo XXI con los parámetros teóricos expuestos aquí.

\section{REFERENCIAS}

Baudrillard, J. (1994). El otro por sí mismo. Barcelona: Anagrama. . (1997). La ilusión del fin o la huelga de los acontecimientos. Barcelona: Anagrama.

Bauman, Z. (2009). Modernidad líquida. Buenos Aires: Fondo de Cultura Económica.

\footnotetext{
${ }^{9}$ Definido por Félix Guattari: "Lo que funda el nuevo paradigma estético es una tensión por apresar la potencialidad creativa que se encuentra en la raíz de la finitud sensible, "antes" de que ella se aplique a las obras, a los conceptos filosóficos, a las funciones científicas, a los objetos mentales y sociales. Las potencialidades de acontecimiento/advenimiento de las velocidades limitadas incluidas en las velocidades infinitas constituye a estas últimas como intensidades creadoras". ("El nuevo paradigma estético", en Dora Fried Schnitman. Nuevos paradigmas, cultura y subjetividad. Buenos Aires: Paidós, 1995, pp. 185-212).
} 
Cánovas, R. (1988). Roberto Merino, Lupe Santa Cruz, Miguel Vicuña Navarro.

"Conversación inconclusa con Enrique Lihn (21 de junio de 1988)." Número quebrado 1 (septiembre-diciembre, 1988), 3-8.

Castro-Gómez, S. (2003). "Latin American Philosophy as critical ontology of the present: Themes and motifs for a "critique of Latin American reason". En Eduardo Mendieta (ed.). Latin American Philosophy. Currents, Issues, Debates (pp. 68-79). Bloomington: Indiana University Press.

Darley, A. (2002). Cultura visual digital. Barcelona: Paidós Ibérica.

Debray, R.(1996). El arcaísmo posmoderno. Lo religioso en la aldea global. Buenos Aires: Editorial Manantial.

Duby, G.(1995). Año 1000, año 2000, la huella de nuestros miedos. Santiago: Editorial Andrés Bello.

Eco, U. (1990). La nueva edad media. Madrid: Alianza Editorial.

Foster, H.(1993). The Anti-Aesthetic. Essays on Postmodern Culture. Seattle: Bay Press.

Foxley, C.(1995). Enrique Lihn, escritura excéntrica y modernidad. Santiago: Editorial Universitaria.

Garrido, M.(2010). "Pena de extrañamiento de Enrique Lihn: La escritura como musa de la calle, el hospital y los museos". Acta Literaria, 41, 69-85.

Guattari, F. (1995). "El nuevo paradigma estético", en Dora Fried Schnitman. Nuevos paradigmas, cultura y subjetividad (pp. 185-212). Buenos Aires: Paidós.

Harvey, D.(1993). The condition of postmodernity. Cambridge, Massachusetts: Blackell Publishers.

Houellebecq, M.(2011). Intervenciones. Barcelona: Anagrama.

Lastra, P. (1986). "Pena de extrañamiento", en ICTUS informa: un espacio de libertad / ICTUS. Santiago: ICTUS, v. N 10, pp. 6-7.

Leach, N. (2001). La an-estética de la arquitectura. Barcelona: Editorial Gustavo Gili.

Lecuna, V. (1999). La ciudad letrada en el planeta electrónico. Madrid: Pliegos.

Lihn, E. (1963). La pieza oscura. Santiago: Editorial Universitaria. - (1966). Poesía de paso. La Habana: Casa de las Américas. . (1975). Por fuerza mayor. Barcelona: Editorial Ocnos. . (1979). A partir de Manhattan. Valparaíso: Ediciones Ganímedes. - (1981). Derechos de autor. Santiago: Yo Editores.

. (1986). Pena de extrañamiento. Santiago: Sinfronteras.

(1987). Mester de juglaría. Madrid: Hiperión

/Poirot, L. (2012). La efímera vulgata. Santiago: Ediciones Universidad Diego Portales.

Lyotard, J. F. (1987). La posmodernidad (explicada a los niños). Barcelona: Gedisa. . (1989). La condición postmoderna: informe sobre el conocimiento. Madrid:

Cátedra.

. (1998). Lo inhumano. Charlas sobre el tiempo. Buenos Aires: Editorial Manantial. 
Maack, A. M. (1985, noviembre). "Enrique Lihn: Creo en todo lo que limita la extensión del Infierno.” El Sur, Concepción, p. v.

Meyronnis, F. (2003). L'Axe du Néant. Paris: Gallimard.

Paz, O. (1983). El signo y el garabato. México: Joaquín Mortiz.

Pohlhammer, E. (1987). "Pena de extrañamiento". Apsi № 203, Santiago, 1 al 7 de junio, p. 51.

Rama, A. (1984). La ciudad letrada. Hannover: Ediciones del Norte.

Rifkin, J. (2000). La era del acceso. La revolución de la nueva economía. Barcelona: Paidós Ibérica.

Sakaiya, T. (1994). Historia del futuro: La sociedad del conocimiento. Santiago: Editorial Andrés Bello.

Santos, L. (2004). Kisch tropical. Madrid: Iberoamericana.

Sarduy, S. (1987). Ensayos generales sobre el barroco. Buenos Aires: Fondo de Cultura Económica.

Sarlo, B. (1998). Escenas de la vida posmoderna. Buenos Aires: Ariel.

Sartori, G. (1998). Homo videns. La sociedad teledirigida. Madrid: Taurus.

Shopf, F. (1986). "Pena de extrañamiento". Pluma y Pincel 18, Santiago, diciembre, p. 51.

Subirats, E. (2004). Una última visión del paraíso. México: Fondo de Cultura Económica.

Travis, C. (2007). Resisting Alienation - The literary work of Enrique Lihn. Lewisburg: Bucknell University Press.

Virilio, P. (1996). El arte del motor. Buenos Aires: Ediciones Manantial. . (1997a). Cibermundo: ¿una política suicida? Santiago: Dolmen Ediciones. . (1997b). La velocidad de liberación. Buenos Aires: Ediciones Manantial. . (1998). La estética de la desaparición. Barcelona: Anagrama. . (2001). El procedimiento silencio. Buenos Aires: Editorial Paidós.

Zapata G., J. (1986, septiembre 14). “Pena de extrañamiento de Enrique Lihn”. El Sur, Concepción, p. v.

. (2003a). "Humanidad, tecnología y reflexión teórica hacia el siglo XXI". (Conferencia no publicada).

. (2003b). "La configuración espacio-temporal postmoderna en los estudios literarios". (Conferencia no publicada). 